\title{
Clinical Value of Serum Vitamin E and FMS-like Tyrosine Kinase-1 in Egyptian Females with Pre-Eclampsia
}

M.A.El-Azouny, A.A.Yousef, E.G.Behiry, I.S.El-Nasr and R.M.Hamoud

Clinical Chemical , Pathology, Gynecology,Obestatric, Dept., Faculty of Medicine, Benha Univ., Benha, Egypt

E-Mail:Ragia26@gmail.com

\begin{abstract}
Were to evaluate serum level of FMS-like Tyrosine Kinase-1 (Flt-1) as a diagnostic utility in pre-eclampsia and its correlation to the severity of the disease, as well as the effect of antioxidant of vitamin E to this level. 20 normotensive pregnancies, 40 Extreme pre-eclamptic tolerant Furthermore 20 gentle pre-eclamptic patients, serum focuses of sFlt-1 Furthermore vitamin e were evaluated with the elisa system. Serum sFlt-1 level $(825.7 \pm 70.0 \mathrm{ng} / \mathrm{l})$ might have been altogether higher over those gentle preeclamptic aggregation (617. $2 \pm 58.4 \mathrm{ng} / \mathrm{l})$ Also both were higher over the normotensive assembly $(475.7 \pm 29$. 1). Vitamin e level might have been altogether easier in the extreme preeclamptic assembly $(0.31 \pm 0.18 \mathrm{mg} / \mathrm{dl})$ over gentle preeclamptic aggregation $(1.00 \pm 0.26 \mathrm{mg} / \mathrm{dl})$ Also both were more level over normotensive gathering $(2.01 \pm 0$. 26). In the preeclampsia group, there might have been An negative correspondence the middle of FMS in tyrosine kinase What's more vitamin e (rho $=-0.557$ and $\mathrm{p}=<0$. 001). Roc bend uncovered that serum Flt-1 at An cut off esteem from claiming $688 \mathrm{ng} / \mathrm{l}$ could anticipate extreme preeclampsia: with a affectability for $97.5 \%$, An specificity of $97.5 \%$, What's more auc $=0.991$. Same time serum vitamin e toward a cut off worth from claiming $0.73 \mathrm{mg} / \mathrm{dl}$ required An affectability about $97.5 \%$, a specificity for $95 \%$ Furthermore auc $=0.984,95 \% \mathrm{CI}=0.96-1.0$ Furthermore $\mathrm{p}<0.001$ in the prediction from claiming extreme preeclampsia. Applying relapse analysis, serum FMS-like tyrosine kinase $\geq 587.7 \mathrm{ng} / \mathrm{l}$ What's more Vit e $\leq 1.06$ $\mathrm{mg} / \mathrm{dl}$ were found should make huge predictors from claiming pre-eclampsia. There is An noteworthy change the middle of FMS-like tyrosine Kinase-1 Furthermore vitamin e levels done preeclampsia Furthermore normotensive pregnancies.
\end{abstract}

Keywords: SFlt-1, Vitamin E, Pre-Eclampsia, Normotensive Pregnancies.

\section{Introduction}

Pre-eclampsia reasons $5 \%-15 \%$ pregnancy issues and will be a standout amongst those three The greater part regular motivations from claiming maternal Furthermore perinatal horribleness and mortality, and in addition spoiling Also discharge [6] the event of pre-eclampsia as stated by WHO (World wellbeing association) is $0.5 \%$ for the sum pregnancies, around 700,000 instances from claiming pre-eclampsia happen every year Also 43,000 of them prompt mortal sin situations [6]. However oversaw economy for indications need been improved, there will be no corrective treatment, What's more just premature labor Also conveyance of the placenta might lessen the mothers' side effects. Atypical placentation prompts faulty uterine vascularization. This outcomes bit by bit faulty perfusion of placental, which induces trophoblast brokenness Also prompts an over the top endothelial dysfunction, glomerular damage and incendiary reaction [9] those danger figures could be collected Similarly as maternal elements (e. G. Hypertension, diabetes mellitus or renal disease) Also placental Components (e. G. Hyperplacentosis, and trophoblastic disease) [12]. The foreseeing factors from claiming pre-eclampsia camwood make found through a few atomic pathways that change pseudo-vasculogenesis. These components comprise of the angiogenic part What's more its receptor. The most recent examination watched the presence from claiming anti-angiogenic proteins that required been processed clinched alongside abundance to maternal circulation, responsible to the phenotype for pre-eclampsia similar to solvent FMS-like tyrosine kinase-1 (sFlt-1)
[2]. Placental solvent FMS like tyrosine kinase-1 (Flt1) which is an foe about vascular endothelial Growth component and placental prompted development figure (PIGF), may be viewed as Likewise a standout amongst the etiologic factors that prompts endothelial harm for pre-eclampsia that transforms vascular endothelial integument [8] Vitamin e may be Similarly as an cell reinforcement goes about Similarly as An forager about spare radicals for example, sensitive oxygen species (e. G. Hydrogen peroxide, superoxide). Free radicals bring those ability to harm Mobile membranes Furthermore nucleic acids, because of its lipid dissolvability [13]. For pre-eclampsia, there need aid diminished emission for enzymatic antioxidants and expanded markers of oxidative anxiety. Supplementation with vitamin e may be still debated What's more need not been demonstrated on make advantageous [18] those point for this fill in might have been on assess serum level from claiming FMS similar to tyrosine kinase 1 Similarly as a symptomatic utility On pre-eclampsia What's more its relationship of the seriousness of the disease, and also those impact of cell reinforcement about vitamin e should this level.

\section{Subjects and methods}

\subsection{Subjects}

This case-control ponder might have been performed looking into 60 pre-eclampsia pregnant females (blood weight rise to or more than 140/90 mmhg ) going to gynaecology \& obstetric Department, at Benha school starting with Walk to december 2017 Also 20 normotensive pregnant females (blood weight rise to or less $120 / 80 \mathrm{mmHg}$ ). 
This examine might have been sanction Eventually Tom's perusing the medicinal moral council for Benha school as stated by the reality medicinal companionship revelation about helsinki (IdänpäänHeikkilä 2001). Patients with pre-eclamptic pregnancy more than 24 weeks from claiming gestation were incorporated in the consider. Patients with constant hypertension, d. M, asthma, other unending ailments alternately taking supplementation about vitamin e were excluded from this investigation. Educated assent might have been gotten from every last bit pregnant females in this consider.

Patients were further subdivided as stated by pulse under two groups: 20 pregnant female for gentle pre-eclampsia (blood weight the middle of 140/90 What's more 160/110 mmhg ), 40 pregnant female with extreme pre-eclamptic pregnancy (blood weight more than 160/110 mmhg ), serum creatinine $<1.1$ $\mathrm{mg} / \mathrm{dl}$, raised liver proteins (ALT, AST), expanded esr and CRP, platelet > 80. 000 and hematocrit < $34 \%)$.

\subsection{Methods}

\section{Participants in the study were subjected to the}

following:

1. Full medical history and clinical examination: blood pressure and vital signs.

2. Laboratory investigations:

\section{Sampling:}

1. Blood samples: nine millilitres venous blood were withdrawn aseptically from all participants and divided into 1 millilitre of blood on K-EDTA to perform $\mathrm{CBC}, 2$ millilitres in citrate tube to perform ESR, and six millilitres in the plain tube and left to clot for $10-15$ minutes, serum was separated by centrifugation at $2000 \mathrm{rpm}$ for 10 minutes. The separated serum was used for clinical chemistry tests (ALT, AST, LDH, and BUN, creatinine, uric acid, and CRP). The rest was stored at $-20{ }^{\circ} \mathrm{C}$ for subsequent measurement of serum level of FMS like tyrosine kinase and serum level of vitamin $\mathrm{E}$.

2. Urine samples: second-morning urine sample was collected in clean dry urine container .

\section{Analytical methods}

CBC was done for all samples using Sysmex XS-800i (Sysmex Corporation, New York, USA) for haemoglobin level, hematocrit value, and platelet count.

Erythrocyte sedimentation using modified Westergren method and Biosystem kits was used to evaluate the quantitative $\mathrm{C}$-reactive protein (CRP).

Biochemical Liver tests- : Alanine aminotransferase (ALT), Aspartate aminotransferase (AST) and Lactate dehydrogenase (LDH) based on enzymatic rate and renal function tests (BUN, creatinine and uric acid) using by Biosystem-A15 instrument, Costa Brava (Barcelona, Spain).
Serum level of FMS-like Tyrosine Kinase-1 and vitamin E were done using ELISA kits supplied by Sunred biotechnology company, (Shanghai, China) with Cat no:(201-12-1976\& 201-12-1548 respectively).

\section{Statistical analysis}

Those gathered information were tabulated Furthermore investigated utilizing SPSS rendition 16 programming (SPSS inc, Chicago, sick organization). Chi-square test (X2), or Fisher's accurate test (FET) were used to examine unmitigated variables. Quantitative information were communicated as intend \pm standard deviation whether regularly disseminated or average What's more IQR though not. Anova or Kruskal-Wallis tests were used to dissect variables Around 3 autonomous aggregations. Same time non-parametric variables were investigated utilizing the mamoncillo Whitney u test. Spearman's relationship coefficient (rho) might have been used to assess liner cooperations the middle of variables. Roc bend might have been used to focus the cutoff esteem with ideal affectability and specificity. Logistic relapse investigation might have been run will recognize those predictors. Those acknowledged level about essentialness in this worth of effort might have been stated at $0.05(\mathrm{P}<0.05$ might have been acknowledged significant).

\section{Results}

This case-control study included 80 pregnant females, sixty of them were pre-eclamptic (Group I), their age ranged between 18-41 years (mean 29.8 \pm 6.38 ), bodyweight ranged between $51-90 \mathrm{Kgs}(73.8$ $\pm 9.35)$ and gestational age was between 25 -38 weeks (31.3 \pm 3.81$)$. Twenty normotensive pregnant females (Group II) matched to the first group in age, weight and GA served as a control group. Pregnant females were classified according to blood pressure level into two groups, the first group included 40 females with severe pre-eclampsia, and the second group included 20 females with mild pre-eclampsia. Full laboratory investigations were summarized in Table (1).

In the severe preeclamptic group, serum sFlt-1 (825.7 $\pm 70.0 \mathrm{ng} / \mathrm{l})$ was significantly higher than mild preeclamptic group $(617.2 \pm 58.4 \mathrm{ng} / \mathrm{l})$ and both were higher than normotensive group (475.7 \pm 29.1$)$. Vitamin E was significantly lower in the severe preeclamptic group $(0.31 \pm 0.18 \mathrm{mg} / \mathrm{dl})$ than the mild preeclamptic group $(1.00 \pm 0.26 \mathrm{mg} / \mathrm{dl})$ and both were lower than normotensive group (2.01 \pm 0.26$)$ Table (1).

In the pre-eclampsia group, there was a negative correlation between FMS like tyrosine kinase and vitamin $\mathrm{E}(\mathrm{rho}=-0.557$ and $\mathrm{p}=<0.001)$. There was a positive correlation between tyrosine kinase and SBP, DBP, liver function tests (ALT, AST, and LDH) and renal function tests (BUN, creat and uric acid), CRP and ESR. Vitamin E was negatively correlated with each of SBP, DBP, liver (ALT, AST, and LDH) 
and renal function tests (BUN, in creat and uric acid), CRP and ESR in preeclampsia group. Neither FMS like tyrosine kinase nor vitamin $\mathrm{E}$ was correlated with any laboratory parameter in the normotensive group Table (2).

Table (1) Comparing the studied groups regarding laboratory investigations.

\begin{tabular}{|c|c|c|c|c|c|c|c|c|c|c|c|}
\hline \multirow[t]{2}{*}{ Variable } & \multicolumn{3}{|c|}{ Severe PE $(n=40)$} & \multicolumn{3}{|c|}{ Mild PE $(n=20)$} & \multicolumn{3}{|c|}{ Normotensive $(\mathbf{n}=\mathbf{2 0})$} & \multirow[t]{2}{*}{ ANOVA } & \multirow[t]{2}{*}{$\mathbf{P}$} \\
\hline & Mean & \pm SD & Range & Mean & \pm SD & Range & Mean & \pm SD & Range & & \\
\hline Hb (gm/dl) & 13.1 & 0.63 & $\begin{array}{c}11.9- \\
14.3\end{array}$ & 12.6 & 0.66 & $\begin{array}{l}10.9- \\
13.5\end{array}$ & 10.6 & 0.69 & $9.8-12$ & 100.5 & $<0.001$ \\
\hline HCT (\%) & 42.3 & 2.78 & $35-47$ & 41.0 & 3.20 & $32-45$ & 31.2 & 2.58 & $28-36$ & 106.8 & $<0.001$ \\
\hline PLTs (c/mm3) & 82.6 & 12.04 & $\begin{array}{l}59- \\
110\end{array}$ & 145.4 & 23.22 & $\begin{array}{l}95- \\
195\end{array}$ & 158.5 & 30.78 & $\begin{array}{l}100- \\
195\end{array}$ & 110.9 & $<0.001$ \\
\hline CRP (mg/l) & 8.46 & 0.58 & $\begin{array}{l}7.2- \\
9.6\end{array}$ & 7.77 & 0.28 & $\begin{array}{l}7.0- \\
8.1\end{array}$ & 5.73 & 1.64 & $\begin{array}{c}4.0- \\
8.0\end{array}$ & 58.3 & $<0.001$ \\
\hline $\operatorname{ESR}(\mathbf{m m} / \mathbf{h r})$ & 86.1 & 5.80 & $74-96$ & 72.8 & 3.07 & $68-78$ & 46.7 & 16.90 & $23-76$ & 115.0 & $<0.001$ \\
\hline $\begin{array}{l}\text { Uric } \\
(\mathrm{mg} / \mathrm{dl})\end{array}$ & 6.69 & 0.76 & $\begin{array}{l}4.7- \\
8.5\end{array}$ & 5.64 & 0.52 & $5-6.5$ & 5.21 & 0.87 & $\begin{array}{c}3.4- \\
6.2\end{array}$ & 30.7 & $<0.001$ \\
\hline BUN (mg/dl) & 5.20 & 0.77 & $\begin{array}{l}3.8- \\
6.5\end{array}$ & 4.30 & 0.39 & $\begin{array}{l}3.8- \\
5.2\end{array}$ & 3.53 & 0.48 & $\begin{array}{l}3.0- \\
4.2\end{array}$ & 48.8 & $<0.001$ \\
\hline $\begin{array}{l}\text { Creatinine } \\
(\mathrm{mg} / \mathrm{dl})\end{array}$ & 1.45 & 0.26 & $\begin{array}{c}1.1- \\
1.9\end{array}$ & 0.94 & 0.15 & $\begin{array}{c}0.7- \\
1.2\end{array}$ & 0.49 & 0.08 & $\begin{array}{c}0.4- \\
0.6\end{array}$ & 146.2 & $<0.001$ \\
\hline ALT (U/I) & 75.7 & 5.92 & $63-88$ & 40.1 & 4.61 & $35-49$ & 18.4 & 5.13 & $7.0-27$ & 809.0 & $<0.001$ \\
\hline AST (U/I) & 47.0 & 7.28 & $32-58$ & 36.4 & 3.25 & $32-41$ & 19.2 & 8.50 & $6.0-30$ & 109.3 & $<0.001$ \\
\hline LDH (U/I) & 742.0 & 78.14 & $\begin{array}{l}615- \\
910\end{array}$ & 594.4 & 23.80 & $\begin{array}{c}520- \\
620\end{array}$ & 295.8 & 43.47 & $\begin{array}{c}250- \\
388\end{array}$ & 218.1 & $<0.001$ \\
\hline $\begin{array}{l}\text { Serum fms-Like } \\
\text { tyrosine kinase- } \\
1 \text { (ng/l) }\end{array}$ & 825.7 & 70.0 & $\begin{array}{c}628- \\
933.2\end{array}$ & 617.2 & 58.4 & $\begin{array}{c}449.5- \\
791\end{array}$ & 475.7 & 29.1 & $\begin{array}{c}449- \\
588.5\end{array}$ & 63.5 & $<0.001$ \\
\hline$\underset{(\mathrm{mg} / \mathrm{dl})}{\operatorname{Serum}}$ vit $E$ & 0.31 & 0.18 & $\begin{array}{c}0.08- \\
1.1\end{array}$ & 1.0 & 0.26 & $\begin{array}{c}0.5- \\
1.9\end{array}$ & 2.01 & 0.26 & $\begin{array}{l}1.05- \\
2.25\end{array}$ & 60.8 & $<0.001$ \\
\hline
\end{tabular}

Table (2) Correlation between serum FMS-Like tyrosine kinase 1 and the studied variables among the studied groups.

\begin{tabular}{|c|c|c|c|c|c|c|c|c|}
\hline \multirow[t]{3}{*}{ With } & \multicolumn{4}{|c|}{ Serum tyrosine kinase } & \multicolumn{4}{|c|}{ Serum vitamin $\mathbf{E}$} \\
\hline & \multicolumn{2}{|c|}{$\begin{array}{c}\begin{array}{c}\text { Pre-eclampsia } \\
(n=60)\end{array} \\
\end{array}$} & \multicolumn{2}{|c|}{$\begin{array}{c}\begin{array}{c}\text { Normotensive } \\
(\mathbf{n}=\mathbf{2 0})\end{array} \\
\end{array}$} & \multicolumn{2}{|c|}{$\begin{array}{c}\text { Pre-eclampsia } \\
(n=60)\end{array}$} & \multicolumn{2}{|c|}{$\begin{array}{c}\begin{array}{c}\text { Normotensive } \\
(\mathbf{n}=\mathbf{2 0})\end{array} \\
\end{array}$} \\
\hline & rho & $\mathbf{P}$ & rho & $\mathbf{P}$ & rho & $\mathbf{P}$ & rho & $\mathbf{P}$ \\
\hline Age (ys) & 0.196 & 0.13 & 0.303 & 0.19 & -0.052 & 0.69 & -0.274 & 0.24 \\
\hline Body weight (kg) & 0.133 & 0.31 & -0.073 & 0.76 & -0.119 & 0.36 & -0.237 & 0.31 \\
\hline $\mathbf{G A}(\mathbf{w})$ & 0.099 & 0.45 & -0.430 & 0.058 & -0.021 & 0.87 & 0.280 & 0.23 \\
\hline Temperature & 0.217 & 0.096 & 0.113 & 0.63 & -0.291 & 0.024 & 0.042 & 0.86 \\
\hline $\mathbf{R R}$ & -0.018 & 0.89 & 0.242 & 0.30 & 0.038 & 0.77 & 0.112 & 0.64 \\
\hline Pulse & 0.072 & 0.58 & -0.181 & 0.44 & 0.047 & 0.72 & 0.071 & 0.77 \\
\hline SBP & 0.632 & $<0.001$ & 0.173 & 0.46 & -0.630 & $<0.001$ & 0.118 & 0.62 \\
\hline DBP & 0.664 & $<0.001$ & 0.291 & 0.23 & -0.643 & $<0.001$ & 0.067 & 0.78 \\
\hline Uric acid & 0.355 & 0.005 & 0.225 & 0.27 & -0.484 & 0.005 & 0.094 & 0.69 \\
\hline LDH & 0.70 & $<0.001$ & 0.099 & 0.68 & -0.566 & $<0.001$ & -0.108 & 0.65 \\
\hline BUN & 0.491 & $<0.001$ & -0.402 & 0.079 & -0.378 & 0.003 & 0.177 & 0.45 \\
\hline Creatinine & 0.659 & $<0.001$ & -0.226 & 0.34 & -0.607 & $<0.001$ & 0.184 & 0.43 \\
\hline ALT & 0.669 & $<0.001$ & 0.059 & 0.81 & -0.650 & $<0.001$ & 0.263 & 0.26 \\
\hline AST & 0.560 & $<0.001$ & 0.122 & 0.61 & -0.483 & $<0.001$ & 0.099 & 0.67 \\
\hline $\mathrm{Hb}$ & 0.063 & 0.63 & -0.005 & 0.98 & -0.314 & 0.015 & -0.149 & 0.53 \\
\hline HCT & 0.012 & 0.93 & 0.016 & 0.95 & -0.174 & 0.18 & -0.246 & 0.29 \\
\hline PLTs & -0.643 & $<0.001$ & -0.140 & 0.55 & 0.668 & $<0.001$ & -0.335 & 0.14 \\
\hline CRP & 0.428 & 0.001 & -0.219 & 0.35 & -0.358 & 0.005 & 0.053 & 0.82 \\
\hline ESR & 0.643 & $<0.001$ & -0.097 & 0.68 & -0.526 & $<0.001$ & 0.315 & 0.17 \\
\hline
\end{tabular}

SBP: systolic blood pressure; DBP: diastolic blood pressure; RR: respiratory rate. 
Table (3) performance of serum FMS-Like tyrosine kinase 1 and Vit E in the prediction of severe preeclampsia.

\begin{tabular}{lcccccccc}
\hline Variable & Cut off & Sens\% & Spec\% & PPV\% & NPV\% & AUC & 95\%CI & P \\
\hline $\begin{array}{l}\text { S. tyrosine } \\
\text { kinase }\end{array}$ & $\geq 688$ & $97.5 \%$ & $97.5 \%$ & $97.5 \%$ & $97.5 \%$ & 0.991 & $0.97-1.0$ & $<0.001$ \\
$\begin{array}{l}\text { Serum vit } \\
\text { E }\end{array}$ & $\leq 0.74$ & $97.5 \%$ & $95 \%$ & $95.1 \%$ & $97.4 \%$ & 0.984 & $0.96-1.0$ & $<0.001$ \\
\hline
\end{tabular}

ROC curve revealed that serum FMS like tyrosine kinase at a cut off value of $688 \mathrm{ng} / \mathrm{l}$ can predict severe pre-eclampsia: with a sensitivity of $97.5 \%$, a specificity of $97.5 \%$, and AUC $=0.991$ and $\mathrm{p}<0.001$. While serum vitamin $\mathrm{E}$ at a cut off value of
$0.73 \mathrm{mg} / \mathrm{dl}$ had a sensitivity of $97.5 \%$, a specificity of $95 \%$ and $\mathrm{AUC}=0.984,95 \% \mathrm{CI}=0.96-1.0$ and $\mathrm{p}<$ 0.001 in the prediction of severe preeclampsia Table (3) \& Fig (3).

Table (4) Binary logistic regression for the predictors of pre-eclampsia.

\begin{tabular}{|c|c|c|c|c|c|c|}
\hline & \multirow[t]{2}{*}{ B } & \multirow[t]{2}{*}{ S.E. } & \multirow[t]{2}{*}{ Sig. } & \multirow[t]{2}{*}{ OR } & \multicolumn{2}{|c|}{ 95.0\% C.I.for EXP(B) } \\
\hline & & & & & Lower & Upper \\
\hline Fms-Like & 4.813 & 1.35 & $<0.001$ & 123.0 & 8.5 & 1762.1 \\
\hline \multicolumn{7}{|c|}{ kinase $1 \geq 587.7$} \\
\hline Vit $\mathrm{E} \leq \mathbf{1 . 0}$ & 3.552 & 1.29 & 0.006 & 34.8 & 2.7 & 442.8 \\
\hline Constant & -3.23 & 1.10 & 0.003 & 0.039 & & \\
\hline
\end{tabular}

Applying regression analysis, serum FMS like tyrosine kinase $\geq 587.7 \mathrm{ng} / \mathrm{l}$ and $\mathrm{Vit} \mathrm{E} \leq 1.06 \mathrm{mg} / \mathrm{dl}$ were found to be significant predictors of Pre-eclampsia $(\mathrm{P}<0.05)$. Table (4).

\section{Discussion}

The possible foreseeing elements connected with pre-eclampsia might be investigated Eventually Tom's perusing the finding for pathways that control vasculogenesis including those angiogenic factors. For pre-eclampsia, there will be diminished emission from claiming enzymatic antioxidants. The undefined alterations Also association the middle of angiogenic markers What's more vitamin e Similarly as antioxidants for pre-eclampsia Also normotensive pregnancies energized us should perform this consider. Exactly writers accepted that the build for this solvent element (sFlt-1) will be those outcome from claiming diminished placental oxygenation [20]. In the extreme preeclamptic group, serum FMS such as tyrosine kinase might have been fundamentally higher over the gentle preeclamptic bunch and both were higher over the normotensive one assembly. Vitamin e might have been altogether bring down in the extreme preeclamptic over those gentle preeclamptic one assembly and both were bring down over the normotensive bunch.

An investigation might have been done Eventually Tom's perusing [13] endorsed that intend serum solvent FMS-like tyrosine kinase 1 focuses were expanded On ladies who formed preeclampsia, compared for typical pregnant women, and this expand might have been mossycup oak maintained over extreme preeclampsia. Lastly, solvent FMS-like tyrosine kinase 1 diminished quickly after delivery, yet all the this decline might have been altogether bring down clinched alongside ladies with extreme preeclampsia.
Patients for preeclampsia required raised s-Flt-1 compared for the particular controls. SFlt-1 might have been not diverse the middle of gentle Also extreme preeclampsia Likewise endorsed Toward those consider finished by [17]. These effects were also affirmed Eventually Tom's perusing [2] who sanction that sFlt-1 serum focuses were higher for ladies with ensuing preeclampsia over to controls (mean \pm SD, sFlt-1: $1764 \pm 757 \mathrm{pg} / \mathrm{mL}$ vs $1537 \pm$ $812 \mathrm{pg} / \mathrm{mL}, \mathrm{p}=$. 036). Sensitivities Furthermore specificities to foreseeing preeclampsia were $64 \%$ Furthermore $56 \%$ for sFlt-1, individually. SFlt-1 need aid expanded in the in the first place trimester Previously, ladies with resulting late-onset preeclampsia and might, therefore, substantiate handy on foresee preeclampsia.

Vitamin e levels were unalterably for slight preeclampsia Nonetheless morals drastically lessened to extreme preeclampsia. The proportion from claiming lipid peroxides will vitamin e might have been increased over direct $(0.52)$ Furthermore considerably increased clinched alongside extreme (1. 09) preeclampsia [19].

Serum vitamin e Furthermore beta-carotene bring been quantified Toward HPLC. The serum vitamin e ranges of the preeclamptic female were $15 \%$ easier over the individuals of the controls $(p<0.01)$ [22]. Ladies with early-onset preeclampsia needed fortythree instances higher average plasma sFlt-1 over controls $\quad(\mathrm{P}<$. 001). Ladies for late-onset preeclampsia were three times higher average plasma sFlt-1 level over late controls $(\mathrm{P}<$. 001) (Wikström et al. 2007). The sFlt-1/PlGF proportion cutoff about 38 built medicinal quality for the non- 
permanent prediction from claiming preeclampsia On asian females with suspected preeclampsia, doubtlessly serving with prevent unnecessary hospitalization and mediation [3]. Vitamin e levels might have been essentially bring down Around preeclamptic situations over the control gathering. Those discoveries of this look into factors accelerated oxidative anxiety Furthermore diminished cell reinforcement phases could likewise conclusion bring about endothelial cell brokenness. The levels from claiming vitamin e Might make used to inspect those seriousness from claiming preeclampsia What's more to different lab parameters (Rani What's more Naidu 2016). Past report card over serum focuses from claiming vitamin e $2.15 \pm 1.3$ and $8.07 \pm 2.3 \mu \mathrm{g} / \mathrm{ml} \mathrm{On}$ preeclampsia What's more sound respectively, they reasoned that degree vitamin e lack Around pregnant females may be an fundamental government funded issue On Kashan, iran [1].

These outcomes were in results of a consider refined Eventually Tom's perusing [20] Concerning illustration the serum levels about vitamin e Also sFlt-1 starting with the gathering of normotensive pregnant and pre-eclampsia ladies indicated a far reaching Contrast $(\mathrm{p}=0.00)$. On the different hand, [ found that there might have been no critical Contrast watched in serum sFlt-1 between the subgroups for preeclampsia $(\mathrm{p}>0.05)$.

Creating preeclampsia might have been essentially expanded "around ladies to each 2-fold rise On sFlt-1 (e. G. Or 2. 18, 95\% ci 1. 46-3. 32), sFlt-1 demonstrated critical contrasts Throughout the third trimester in ladies who create preeclampsia compared for fitting controls altogether elevated structure bunches. Main sFlt-1 might have been essentially higher 2 with 5 weeks in front of the clinical onset of preeclampsia What's more just Previously, ladies for past preeclampsia Likewise An investigation Toward [14]. Utilizing biomarkers Likewise a placental Growth element (PlGF), sFlt-1, dissolvable endoglin (sEng) in the prediction about pre-eclampsia which were decided Toward elisa test. They found that the best predictor for pe might have been PIGF with a affectability about $100 \%$ In An centralization edge about $120.16 \mathrm{pg} / \mathrm{mL}$, the symptomatic correctness about $70.8 \%$, What's more auc of $0.684(\mathrm{p}=0.005)$.

[11] mulled over connection the middle of maternal imply blood vessel pressure, brachial corridor flow-mediated dilatation, What's more serum focuses for PlGF, dissolvable FMS-like tyrosine kinase 1 (sFlt-1), found that ladies who created preterm preeclampsia required higher sFlt-1: PlGF proportion $(\mathrm{P}=0$. 005) compared with ladies who later produced haul preeclampsia.

A few investigations bring indicated that placenta of pre-eclamptic secretes a lot for superoxide with decreased focuses of antioxidants, oxidative anxiety What's more placental hypoxia climbs the preparation from claiming lipid peroxidation. Amazing lipid peroxidation required expansive amounts of antioxidants, Furthermore prompt decreased serum focuses of antioxidants for example, such that vitamin $\mathrm{E}$, that is recognized those The majority suitableness cell reinforcement to keep free radical handling from lipid oxidation, exactly researchs attempted with provide for vitamin e supplementation to decrease those placental oxidative stress [20]. We finished up that there is a noteworthy expand over levels for sFlt-1 Furthermore An decline clinched alongside vitamin e for pre-eclampsia over normotensive pregnant ladies. Expanded serum sFlt-1 Also diminished vitamin e needed An solid association for those occurrence about pre-eclampsia. Both were huge predictors of Pre-eclampsia. Revelation Statement: no clash of investment.

\section{References}

[1] Z.Asemi, M.Taghizadeh, S.Sarahroodi,. Assessment of the relationship of vitamin D with serum antioxidant vitamins $\mathrm{E}$ and $\mathrm{A}$ and their deficiencies in Iranian pregnant women. Saudi Medical, Vol.31,PP.1119-23. 2010

[2] M.U.Baumann, N.A.Bersinger, M.G.Mohaupt, First-trimester serum levels of soluble endoglin and soluble fms-like tyrosine kinase- 1 as firsttrimester markers for late-onset preeclampsia. American J.,obstetrics and gynecology, Vol.14,PP.198-201,1995.

[3] X.Bian, A.Biswas, X.Huang, Short-Term Prediction of Adverse Outcomes Using the sFlt1 (Soluble fms-Like Tyrosine Kinase 1)/PIGF (Placental Growth Factor) Ratio in Asian Women With Suspected Preeclampsia. Hypertension, Vol.74, PP.164-72. 2019

[4] J.E,Chiegil.Assessment of Quality of Life from HIV Counselling and Social Support among PLWHA Clinic Attendees in Specialist Hospital Yola, Adamawa State, Nigeria. Assessment. Vol.5,pp15-116(4). 2017

[5] N.Cim, M.Kurdoglu, S.Ege, An analysis of the roles of angiogenesis-related factors including serum vitamin D, soluble endoglin (sEng), soluble fms-like tyrosine kinase 1 (sFlt1), and vascular endothelial growth factor (VEGF) in the diagnosis and severity of late-onset preeclampsia. The J.,Maternal-Fetal \& Neonatal Medicine. Vol.30,PP.1602-7. 2017

[6] F.Cunningham, K.Leveno, S.Bloom, Williams obstetrics, 24e. Mcgraw-hill vol.14,PP.198-201, 2014

[7] S.P.Emery,Hypertensive, disorders of pregnancy: Overdiagnosis is appropriate. Cleveland Clinic J.,medicine vol.72,PP.345352. 2005

[8] J.I.Gurnadi, J.Mose, B.Handono, Difference of concentration of placental soluble fms-like tyrosine kinase-1 (sFlt-1), placental growth 
factor (PlGF), and sFlt-1/PlGF ratio in severe preeclampsia and normal pregnancy. BMC research notes vol.10,PP.192-201,2015

[9] J.E,Idänpään-Heikkilä, Ethical principles for the guidance of physicians in medical research: the Declaration of Helsinki ,Vol.11,PP.279-279. 2001

[10] E.Lecarpentier, V.Tsatsaris, Angiogenic balance (sFlt-1/PlGF) and preeclampsia. In Annales d'endocrinologie ,vol.77, PP.97-100. 2016

[11] M,Noori, AE.Donald, A.Angelakopoulou. Clinical perspective. Circulation, vol.122,pp 478-87. 2010

[12] K.O.Osungbade, OK.Ige, Public health perspectives of preeclampsia in developing countries: implication for health system strengthening. J.,pregnancy 2011.

[13] RW.Powers, A.Jeyabalan, RG.Clifton,. Soluble fms-Like tyrosine kinase 1 (sFlt1), endoglin and placental growth factor (PlGF) in preeclampsia among high risk pregnancies. PloS one Vol.5,pp13-63. 2010

[14] R.W.Powers, JM.Roberts, KM.Cooper, Maternal serum soluble fms-like tyrosine kinase 1 concentrations are not increased in early pregnancy and decrease more slowly postpartum in women who develop preeclampsia. American J.,obstetrics and gynecology Vol.193,pp 185-191.2000

[15] C.Rădulescu, A.Bacârea, A.Huțanu, Placental growth factor, soluble fms-like tyrosine kinase 1, soluble endoglin, IL-6, and IL-16 as biomarkers in preeclampsia. Mediators of inflammation vol.14,PP.198-201 2016.

[16] N.A.Rani, J.N.Naidu, Appraisal of Oxidative Stress Markers, Vitamin E and their Correlation with Blood Pressure in Preeclampsia: A Case Control Study. International J.,Clinical Biochemistry and Research vol.3,PP.11-5 2016

[17] C.J.Robinson, D.D.Johnson, E.Y.Chang, .. Evaluation of placenta growth factor and soluble Fms-like tyrosine kinase 1 receptor levels in mild and severe preeclampsia. American J.,obstetrics and gynecology vol.195,PP.255-259. 2006

[18] A.Wang, S.Rana, SA.Karumanchi. Preeclampsia: the role of angiogenic factors in its pathogenesis. Physiology Vol.24,PP.147158. 2009

[19] Y.Wang, S.W.Walsh, J.Guo,. The imbalance between thromboxane and prostacyclin in preeclampsia is associated with an imbalance between lipid peroxides and vitamin $\mathrm{E}$ in maternal blood. American J.,obstetrics and gynecology,vol.165,PP.1695-1700. 1991

[20] J.Wantania, M.Durry, J.Bernadus.. The Level of Soluble FMS-Like Tyrosinkinase-1, Placental Growth Factor and Vitamin E in Pre-Eclampsia and Normotensive Pregnancy. International J.,Clinical Medicine vol.6,PP.4-75. 2015

[21] A.K.Wikström, A.Larsson, UJ.Eriksson, Nordén-Lindeberg S, Olovsson M.. Placental growth factor and soluble FMS-like tyrosine kinase-1 in early-onset and late-onset preeclampsia. Obstetrics \& Gynecology ,vol.109,PP.1368-74. 2007

[22] S.A.Ziari, V.L.Mireles, C.G.Cantu, vitamin E, and beta-carotene levels in preeclamptic women in northern Nigeria. American J.,perinatology ,Vol.13,PP.287-291. 1996 
